\title{
Impact of risk aversion and countervailing tax in oligopoly
}

\author{
Jim Y. Jin ${ }^{1}$ - Shinji Kobayashi
}

Received: 4 August 2016 / Accepted: 7 November 2016 / Published online: 16 November 2016 (C) The Author(s) 2016. This article is published with open access at Springerlink.com

\begin{abstract}
The literature recognizes the qualitative effects of risk aversion on oligopolistic market performance, but less is known about their magnitudes. We quantitatively evaluate these effects in Cournot and Bertrand oligopolies where firms maximize mean-variance utilities under linear demand and costs. The impacts are very similar for the two types of oligopoly, but have opposite signs. The impacts of a firm's risk aversion on outputs, prices, consumer surplus and social welfare can be expressed via potentially observable variables. Since these impacts resemble the effects of firms' cost changes, a regulator can reduce or eliminate undesirable effects of risk aversion by changing firms' costs with appropriate countervailing taxes.
\end{abstract}

Keywords Risk aversion · Quantity versus price competition · Welfare effect · Unit tax

JEL Classification D43 - D81 $\cdot$ L13

We thank Rabah Amir for his valuable comments and suggestions. Kobayashi's work was partially supported by JSPS KAKENHI Grant Number JP15K03462.

$凶 \quad \operatorname{Jim}$ Y. Jin

jyj@st-andrews.ac.uk

Shinji Kobayashi

kobayashi.shinji@nihon-u.ac.jp

1 School of Economics and Finance, University of St Andrews, St Andrews KY16 9AL, UK

2 Graduate School of Economics, Nihon University, 1-3-2 Misaki, Chiyoda, Tokyo 101-8360, Japan 


\section{Introduction}

Firms' behavior under uncertainty can be strongly affected by risk aversion. For the case of banks, this is clearly demonstrated by the recent financial crisis, during which big banks' behavior changed dramatically and led to significant consequences. For instance, inter-bank loans shrank to nearly zero after the downfall of Lehman Brothers in 2008 and this unexpected reaction put the global financial market at a serious risk. To understand this phenomenon, we need to know not only the qualitative features of the impact of risk aversion, but also its magnitude. This will help us find appropriate approaches to reduce or eliminate the undesirable effects of changes in risk aversion.

The literature has shown that firms' risk-aversion affects the market differently under quantity and price competition. Sandmo (1971) and Batra and Ullah (1974) first discovered that competitive firms facing price uncertainty would reduce production. This also holds true for monopoly firms choosing outputs (Baron 1971; Leland 1972; Hau 2004). However, as Baron points out, the reverse holds if a monopolist faces an uncertain quantity and chooses its price. Later researchers extended this analysis to oligopoly and examined the impact of risk aversion under both demand and cost uncertainty. Wambach (1999) finds that Bertrand firms selling homogeneous goods can retain positive price margins, instead of zero, when they do not know each other's costs. Similarly, Cheng (2002) shows that unknown costs allow positive profits for Bertrand firms even when their number increases to infinity, in contrast to Cournot oligopoly. ${ }^{1}$ Asplund (2002) further examines Cournot and Bertrand duopolies with demand uncertainty, and shows that risk aversion reduces a firm's decision variable (output or price) and reduces (increases) the rival's decision if their decisions are strategic complements (substitutes). These studies mainly focus on the qualitative impact of risk aversion, not on its quantitative evaluation.

The quantitative evaluation of the impact of risk aversion is especially important in asymmetric oligopolies, where the impact is complicated due to strategic interaction. Without quantitative evaluation, we have little idea of how vulnerable a market is to sudden changes in risk aversion, and cannot find effective measures to eliminate undesirable effects. Thus we need to examine its magnitude and investigate how to counterbalance these effects if needed. A well-known example of this counterbalancing policy is the so-called Tobin tax (Tobin 1978), which can be imposed on financial transactions to discourage risky speculation. Following his idea the literature has studied the feasibility and optimal level of a Tobin tax (Eichengreen et al. 1995). However, little attention has been given to risk attitude, which is closely related to the intensity of speculation. In this paper we look for a countervailing tax in general Cournot and Bertrand oligopolies, instead of foreign exchange or financial markets for which the Tobin tax is usually considered.

We consider the impact of a firm's risk aversion in linear oligopolies where firms have mean-variance utilities. ${ }^{2}$ This simple model allows us to solve for the equilibrium

\footnotetext{
1 Spulber (1995) and Janssen and Rasmusen (2002) also obtain positive expected profits in Bertrand oligopoly with unknown costs or the number of firms, respectively.

2 Since Markowitz (1952) and Tobin (1958), mean-variance utility has been well justified for quadratic utility functions and normal distributions. It is also valid approximately for a wide variety of concave
} 
in closed-form while capturing risk effects on the part of firms. In addition, we deviate from the traditional literature that assumes at the outset a standard Cournot or Bertrand equilibrium based on firms' fully rational decisions, which would require unrealistic information, including knowing other firms' risk aversion parameters. As risk aversion is unobservable by other firms, we do not assume that firms make decisions with such information on hand, but rather that they follow naïve learning decision rules reflecting limited rationality. ${ }^{3}$ The equilibrium is defined as a steady state where all firms repeat their previous decisions and their expectations are realized. We evaluate the impacts of a firm's risk aversion on outputs, prices, consumer surplus and social welfare as expressed via potentially observable variables, thus excluding in particular unobservable risk aversion. We find that these impacts are very similar but that they act in opposite directions in Cournot and Bertrand oligopolies. In addition, they resemble the effects of firms' exogenous cost changes on market performance. Hence we can offset the undesirable effects of risk aversion and even eliminate them by changing firms' costs with appropriate countervailing taxes.

The next section introduces our Cournot and Bertrand oligopoly models. We then present a special case of monopoly in Sect. 3 to illustrate and contrast the different impacts of risk aversion when the firm chooses its output versus its price. We evaluate the impact of risk aversion in Cournot and Bertrand oligopolies in Sect. 4. Section 5 discusses the use of countervailing taxes to eliminate the undesirable effects of risk aversion. Section 6 concludes the paper and proofs are in the Appendices.

\section{The Cournot and Bertrand models}

We first introduce a linear and asymmetric oligopoly model. There are $n+1$ goods: a numeraire good $x_{0}$ with a price normalized to 1 and $n$ differentiated goods grouped in an $n \times 1$ product vector $\boldsymbol{x}$. Good $i$ is produced by firm $i$ at a constant marginal cost $c_{i}$. We denote the $n \times 1$ cost vector by $c$. The representative consumer has a quadratic utility function $u=x_{0}+\boldsymbol{a}^{\prime} \boldsymbol{x}-0.5 \boldsymbol{x}^{\prime} \boldsymbol{B} \boldsymbol{x}$, where $\boldsymbol{a}$ is a positive $n \times 1$ vector, $\boldsymbol{B}$ is an $n \times n$ matrix. Without loss of generality, we let $\boldsymbol{B}$ be symmetric and assume it is positive definite, so $u$ is strictly concave in $\boldsymbol{x}$. Denote the elements of $\boldsymbol{B}$ by $b_{i j}$ for all $i$ and $j$. As $\boldsymbol{B}$ is symmetric and positive definite, so is its inverse $\boldsymbol{B}^{-1}$. Denote the elements of $\boldsymbol{B}^{-1}$ by $\beta_{i j}$ for all $i$ and $j$. Diagonal elements $b_{i i}>0$ and $\beta_{i i}>0$, but the signs of off-diagonal elements $b_{i j}$ and $\beta_{i j}$ are unspecified for $j \neq i$, allowing for any mixture of complementary and substitute goods.

Let $p_{i}$ be the price of good $i$ and $\boldsymbol{p}$ be the price vector. The representative consumer has a fixed income $W$ and chooses a consumption bundle $x$ to maximize her utility given her budget constraint $x_{0}+\boldsymbol{p}^{\prime} \boldsymbol{x} \leq W$. We assume that $W$ is sufficiently high so

Footnote 2 continued

(risk-averse) utility functions, as argued by Levy and Markowitz (1979) and Markowitz (2014). See also recent reappraisals by Eichner and Wagener (2009, 2014).

3 See Herranz et al. (2015) for a case where it was possible to estimate the distribution of risk aversion using firm data. Even when it is possible to estimate the distribution an individual firm would not have this information. 
that an interior solution exists ${ }^{4}$. Since $u$ is strictly concave in $\boldsymbol{x}$, the demand vector $\boldsymbol{x}$ can be solved from the first-order condition $\boldsymbol{a}-\boldsymbol{B} \boldsymbol{x}-\boldsymbol{p}=\mathbf{0}$. This implies an inverse demand function for an $n$-firm Cournot oligopoly as $\boldsymbol{p}=\boldsymbol{a}-\boldsymbol{B} \boldsymbol{x}$, i.e.

$$
p_{i}=a_{i}-\sum_{j=1}^{n} b_{i j} x_{j} \quad \text { for all } i
$$

From the first-order condition $\boldsymbol{a}-\boldsymbol{B} \boldsymbol{x}-\boldsymbol{p}=\mathbf{0}$, we can solve the direct demand function for an $n$-firm Bertrand oligopoly as $\boldsymbol{x}=\boldsymbol{\alpha}-\boldsymbol{B}^{-1} \boldsymbol{p}$, where $\boldsymbol{\alpha}=\boldsymbol{B}^{-1} \boldsymbol{a}$, i.e.

$$
x_{i}=\alpha_{i}-\sum_{j=1}^{n} \beta_{i j} p_{j} \quad \text { for all } i
$$

Firm $i$ 's profit is $\pi_{i}=x_{i}\left(p_{i}-c_{i}\right)$, where $p_{i}$ is given by (1) in Cournot oligopoly. In Bertrand oligopoly, $x_{i}$ is given by (2). As firms do not know their prices or quantities, their profits are unknown and have variance $V\left(\pi_{i}\right)$. We assume each firm $i$ maximizes a mean-variance utility function, with risk aversion coefficient $\delta_{i}$, given by

$$
v_{i}=E\left(\pi_{i}\right)-\delta_{i} V\left(\pi_{i}\right) \text { for all } i
$$

When a Cournot firm chooses $x_{i}$ to maximize (3), it perceives its price $p_{i}$ as a random variable with variance $\sigma_{i}^{2}$. So the profit variance $V\left(\pi_{i}\right)=x_{i}^{2} V\left(p_{i}-c_{i}\right)=x_{i}^{2} \sigma_{i}^{2}$ and its utility function (3) becomes $x_{i} E\left(p_{i}-c_{i}\right)-\delta_{i} \sigma_{i}^{2} x_{i}^{2}$. When a Bertrand firm chooses $p_{i}$ to maximize (3), it perceives its quantity $x_{i}$ as a random variable with variance $\rho_{i}^{2}$. The profit variance $V\left(\pi_{i}\right)=\left(p_{i}-c_{i}\right)^{2} V\left(x_{i}\right)=\left(p_{i}-c_{i}\right)^{2} \rho_{i}^{2}$, and its utility function (3) becomes $\left(p_{i}-c_{i}\right) E\left(x_{i}\right)-\delta_{i} \rho_{i}^{2}\left(p_{i}-c_{i}\right)^{2}$.

The literature usually evaluates the impact of risk aversion on the Cournot-Nash or Bertrand-Nash equilibrium outcomes. The implicit assumption then is that firms know their own and rivals' profit functions and risk aversion parameters. This is rather unrealistic especially in an asymmetric oligopoly where firms should not know each other's risk aversion. Instead we assume that firms choose their output quantities or prices in each period $t$ with limited information and their decisions converge to an equilibrium through a learning process. Firms do not know rivals' demand, costs and risk aversion, and cannot anticipate their decisions. Moreover, they do not know their own demand functions precisely, including key parameters such as $a_{i}$ and $\alpha_{i}$, which may be the source of demand uncertainty. A firm knows only the slope of its demand curve, $b_{i i}$ or $\beta_{i i}$, its own cost $c_{i}$, risk aversion $\delta_{i}$, the previous price and quantity, $p_{i t-1}$ and $x_{i t-1}$, and variance $\sigma_{i}^{2}$ or $\rho_{i}^{2}$. Given this limited information each firm follows a simple rule to choose $x_{i t}$ or $p_{i t}$ to maximize (3).

As a reflection of bounded-rationality, an equilibrium here is defined as a steady state where all firms repeat their previous decisions and their expected prices or demands are realized. While this steady state turns out to be identical to the Nash equilibrium outcome used in the literature, it is achieved through a repeated simple adjustment

\footnotetext{
4 While $\boldsymbol{B}$ 's positive definiteness is a necessary condition for our linear demand, a sufficient income $W$ may not hold when goods are complements and the determinant $|\boldsymbol{B}|$ is close to zero [see Amir et al. (2015)].
} 
process based on realistic information, either in quantities or in prices, rather than by firms' rational decisions based on complete and far-reaching information, including rivals' risk aversion parameters.

In the next section we first present a special case of oligopoly with $n=1$, i.e. monopoly. It serves as an example for our general Cournot and Bertrand oligopolies. Without strategic interaction, a monopoly firm can easily find its optimal price or output with limited information. We will show that the impacts of risk aversion go in opposite directions when the firm chooses price and output, as pointed out by Baron (1971). Given our linear model, we can precisely determine the impact of a monopolist's risk aversion on its output, price, consumer surplus and social welfare. We then extend our result from a single-good monopoly to a multi-product monopoly.

\section{Monopoly}

In this section we use the simple case of monopoly to illustrate some of the main ideas of the paper without taking into account strategic interaction among firms. We show the opposite impacts of risk aversion on market performance when the firm chooses its quantity versus its price.

\subsection{Quantity setting monopoly}

We first consider a special case of our Cournot oligopoly model with $n=1$, i.e. a quantity setting monopoly. In this case the inverse demand function (1) in period $t$ reduces to $p_{t}=a-b x_{t}$, and the profit $\pi_{t}=x_{t}\left(p_{t}-c\right)$. As $V\left(\pi_{t}\right)=x_{t}^{2} \sigma^{2}$, the utility function (3) becomes $v_{t}=x_{t} E\left(p_{t}-c\right)-\delta x_{t}^{2} \sigma^{2}$. The first-order condition for $x_{t}$ to maximize $v_{t}$ is $E\left(p_{t}\right)-c-b x_{t}-2 \delta x_{t} \sigma^{2}=0$. The best estimate of $p_{t}$ is to adjust its previous price by the change in output, i.e. $E\left(p_{t}\right)=p_{t-1}-b\left(x_{t}-x_{t-1}\right)$. Substituting this into the first-order condition, we have $p_{t-1}-b\left(x_{t}-x_{t-1}\right)-c-b x_{t}-2 \delta x_{t} \sigma^{2}=0$. Thus, based on this limited information, the monopolist should choose its output to be $x_{t}=\frac{p_{t-1}-c+b x_{t-1}}{2\left(b+\delta \sigma^{2}\right)}$. Since $p_{t-1}=a-b x_{t-1}, x_{t}$ must be equal to the optimal output $x=\frac{a-c}{2\left(b+\delta \sigma^{2}\right)}$, which indeed maximizes $v_{t}$, even though the monopolist may not directly observe the value of $a$.

Then we can evaluate the impact of risk aversion on the output, price, social welfare and consumer surplus. The impact on the output is $\frac{\partial x}{\partial \delta}=-\frac{(a-c) \sigma^{2}}{2\left(b+\delta \sigma^{2}\right)^{2}}<0$. From the inverse demand $p=a-b x$, we have $\frac{\partial p}{\partial \delta}=-b \frac{\partial x}{\partial \delta}>0$. Moreover, as social welfare $(S W)$ is equal to $(a-c) x-0.5 b x^{2}$, we get $\frac{\partial S W}{\partial \delta}=(a-c-b x) \frac{\partial x}{\partial \delta}=(p-c) \frac{\partial x}{\partial \delta}<0$. As consumer surplus is equal to $0.5 b x^{2}$, we find $\frac{\partial C S}{\partial \delta}=b x \frac{\partial x}{\partial \delta}<0$. Hence risk aversion in a quantity setting monopoly harms both consumers and society.

We also find that $\frac{\partial S W}{\partial \delta}+\frac{\partial C S}{\partial \delta}=(p-c+b x) \frac{\partial x}{\partial \delta}=(a-c) \frac{\partial x}{\partial \delta}=-\frac{(a-c)^{2} \sigma^{2}}{2\left(b+\delta \sigma^{2}\right)^{2}}=$ $-2 x^{2} \sigma^{2}=-2 V(\pi)$. So the negative impact of risk aversion on the sum of consumer surplus and social welfare is exactly twice the profit variance. Surprisingly, this simple result also holds in a multi-product monopoly.

Now we extend the single-good monopoly to a monopolist selling $n$ differentiated products as described in our oligopoly model. Then the monopolist total profit becomes 
$\pi=(\boldsymbol{p}-\boldsymbol{c})^{\prime} \boldsymbol{x}$. The quantity setting monopolist faces an uncertain price vector $\boldsymbol{p}$ whose $\mathrm{n} \times \mathrm{n}$ variance and covariance matrix $\operatorname{Cov}(\boldsymbol{p}) \equiv \boldsymbol{\Sigma}$, which must be symmetric and positive definite. So the variance of profit $V(\pi)=\boldsymbol{x}^{\prime} \boldsymbol{\Sigma} \boldsymbol{x}$, and the objective function (3) becomes

$$
v_{t}=\boldsymbol{x}_{t}^{\prime} E\left(\boldsymbol{p}_{t}-c\right)-\delta \boldsymbol{x}_{t}^{\prime} \boldsymbol{\Sigma} \boldsymbol{x}_{t}
$$

The first-order condition for $\boldsymbol{x}_{t}$ to maximize $\left(3^{\prime}\right)$ is $E\left(\boldsymbol{p}_{t}\right)-\boldsymbol{c}-\boldsymbol{B} \boldsymbol{x}_{t}-2 \delta \boldsymbol{\Sigma} \boldsymbol{x}_{t}=\mathbf{0}$. The monopolist may estimate $E\left(\boldsymbol{p}_{t}\right)=\boldsymbol{p}_{t-1}-\boldsymbol{B}\left(\boldsymbol{x}_{t}-\boldsymbol{x}_{t-1}\right)$. Since matrix $\boldsymbol{B}+\delta \boldsymbol{\Sigma}$ is positive definite, we can solve the optimal output in period $t, \boldsymbol{x}_{t}=0.5(\boldsymbol{B}+\delta \boldsymbol{\Sigma})^{-1}\left(\boldsymbol{p}_{t-1}-\right.$ $\left.\boldsymbol{c}+\boldsymbol{B} \boldsymbol{x}_{t-1}\right)$. As $\boldsymbol{p}_{t-1}=\boldsymbol{a}-\boldsymbol{B} \boldsymbol{x}_{t-1}, \boldsymbol{x}_{t}$ must be equal to the true optimal output $\boldsymbol{x}=0.5(\boldsymbol{B}+\delta \boldsymbol{\Sigma})^{-1}(\boldsymbol{a}-\boldsymbol{c})$. When $\delta=0$, the multi-product monopoly output $\boldsymbol{x}=$ $0.5 \boldsymbol{B}^{-1}(\boldsymbol{a}-\boldsymbol{c})$, which is equal to half the socially optimal quantity, as obtained by Amir et al. (2016).

Given this result, we can evaluate the impact of risk aversion on outputs, prices, social welfare and consumer surplus. However, for simplicity, we only present the effect on the sum of social welfare and consumer surplus (see "Appendix 1").

Proposition 1 In a quantity setting multi-product monopoly, the effect of risk aversion on the sum of social welfare and consumer surplus, $\frac{\partial S W}{\partial \delta}+\frac{\partial C S}{\partial \delta}=-2 V(\pi)$.

Hence the simple result from a single-good monopoly holds in a multi-product monopoly. We will show a similar result in our Cournot oligopoly in Sect. 4.

\subsection{Price setting monopoly}

Similarly, we consider a case of Bertrand oligopoly with $n=1$, i.e. a price setting monopolist. In this case the demand function (2) in period $t$ reduces to $x_{t}=\left(a-p_{t}\right) / b$, and the profit $\pi_{t}=x_{t}\left(p_{t}-c\right)$. As $V\left(\pi_{t}\right)=\left(p_{t}-c\right)^{2} \rho^{2}$, the utility function (3) is equal to $v_{t}=\left(p_{t}-c\right) E\left(x_{t}\right)-\left(p_{t}-c\right)^{2} \delta \rho^{2}$. Then the first-order condition for $p_{t}$ to maximize $v_{t}$ is $E\left(x_{t}\right)-\left(p_{t}-c\right) / b-2\left(p_{t}-c\right) \delta \rho^{2}=0$. The best estimate of $x_{t}$ is to adjust its previous quantity by a change in its price, i.e. $E\left(x_{t}\right)=x_{t-1}-\left(p_{t}-p_{t-1}\right) / b$. Substitute this into the first-order condition, we have $x_{t-1}-\left(p_{t}-p_{t-1}\right) / b-\left(p_{t}-\right.$ $c) / b-2\left(p_{t}-c\right) \delta \rho^{2}=0$. Thus, based on the limited information, the monopolist should choose its price as $p_{t}=c+\frac{b x_{t-1}+p_{t-1}-c}{2\left(1+\delta b \rho^{2}\right)}$. As $x_{t-1}=\left(a-p_{t-1}\right) / b, p_{t}$ must be equal to the optimal price $p=c+\frac{a-c}{2\left(1+\delta b \rho^{2}\right)}$, which maximizes the utility $v_{t}$, even though the monopolist may not observe the value of $a$.

Again we evaluate the impact of risk aversion on the output, price, social welfare and consumer surplus. The impact on the price is $\frac{\partial p}{\partial \delta}=-\frac{(a-c) b \rho^{2}}{2\left(1+\delta b \rho^{2}\right)^{2}}<0$. As the output $x=\frac{a-p}{b}$, we have $\frac{\partial x}{\partial \delta}=-\frac{1}{b} \frac{\partial p}{\partial \delta}>0$. Moreover, as social welfare is $(a-c) x-0.5 b x^{2}$, we get $\frac{\partial S W}{\partial \delta}=(p-c) \frac{\partial x}{\partial \delta}>0$. As consumer surplus is $0.5 b x^{2}, \frac{\partial C S}{\partial \delta}=b x \frac{\partial x}{\partial \delta}>0$. Hence, risk aversion by a price setting monopolist benefits consumers and the society.

We also obtain $\frac{\partial S W}{\partial \delta}+\frac{\partial C S}{\partial \delta}=(a-c) \frac{\partial x}{\partial \delta}=-\frac{a-c}{b} \frac{\partial p}{\partial \delta}=\frac{(a-c)^{2} \rho^{2}}{2\left(1+\delta b \rho^{2}\right)^{2}}$, which is equal to $2(p-c)^{2} \rho^{2}=2 V(\pi)$. So the positive impact of risk aversion on the sum of consumer surplus and social welfare is twice the profit variance, exactly 
opposite to the quantity-setting monopolist. This result also holds in a multi-product monopoly.

We now extend the single-good monopolist problem to a multi-product monopolist. The total profit is still $\pi=(\boldsymbol{p}-\boldsymbol{c})^{\prime} \boldsymbol{x}$. The price setting monopolist faces an uncertain output vector $\boldsymbol{x}$, whose $n \times n$ variance and covariance matrix $\operatorname{Cov}(\boldsymbol{x}) \equiv \boldsymbol{\Omega}$, which must be symmetric and positive definite. So the profit variance $V(\pi)=(\boldsymbol{p}-\boldsymbol{c})^{\prime} \boldsymbol{\Omega}(\boldsymbol{p}-\boldsymbol{c})$, and the objective function (3) becomes:

$$
v_{t}=\left(\boldsymbol{p}_{t}-c\right)^{\prime} E\left(\boldsymbol{x}_{t}\right)-\delta\left(\boldsymbol{p}_{t}-\boldsymbol{c}\right)^{\prime} \boldsymbol{\Omega}\left(\boldsymbol{p}_{t}-\boldsymbol{c}\right)
$$

The first-order condition to maximize (3") is $E\left(\boldsymbol{x}_{t}\right)-\boldsymbol{B}^{-1}\left(\boldsymbol{p}_{t}-\boldsymbol{c}\right)-2 \delta \boldsymbol{\Omega}\left(\boldsymbol{p}_{t}-\boldsymbol{c}\right)=\mathbf{0}$. The monopolist may estimate $E\left(\boldsymbol{x}_{t}\right)=\boldsymbol{x}_{t-1}-\boldsymbol{B}^{-1}\left(\boldsymbol{p}_{t}-\boldsymbol{p}_{t-1}\right)$. Since matrix $\boldsymbol{B}^{-1}+\delta \boldsymbol{\Omega}$ is positive definite, the optimal price $\boldsymbol{p}_{t}=\boldsymbol{c}+0.5\left(\boldsymbol{B}^{-1}+\delta \boldsymbol{\Omega}\right)^{-1}\left[\boldsymbol{x}_{t-1}+\boldsymbol{B}^{-1}\left(\boldsymbol{p}_{t-1}-\boldsymbol{c}\right)\right]$. As $\boldsymbol{p}_{t-1}=\boldsymbol{a}-\boldsymbol{B} \boldsymbol{x}_{t-1}, \boldsymbol{p}_{t}$ must be equal to the true optimal price $\boldsymbol{p}=\boldsymbol{c}+0.5(\boldsymbol{I}+$ $\delta \boldsymbol{B} \boldsymbol{\Omega})^{-1}(\boldsymbol{a}-\boldsymbol{c})$. If $\delta=0$, we get $\boldsymbol{p}=0.5(\boldsymbol{a}+\boldsymbol{c})$, i.e. all monopoly prices are independent of each other, a result obtained in Amir et al. (2016). With risk aversion, the price independence breaks down even if all quantities demanded are uncorrelated, i.e. when $\boldsymbol{\Omega}$ is diagonal.

Given the optimal prices, we can evaluate the impact of risk aversion on outputs, prices, social welfare and consumer surplus. However, for simplicity, we only present the effect on the sum of social welfare and consumer surplus (see "Appendix 2").

Proposition 2 In a price setting multi-product monopoly, the effect of risk aversion on the sum of social welfare and consumer surplus is $\frac{\partial S W}{\partial \delta}+\frac{\partial C S}{\partial \delta}=2 V(\pi)$.

Hence the simple result from a single-good monopoly again holds in a price setting multi-product monopoly. We will show a similar result in Bertrand oligopoly.

The impacts of risk aversion can be expressed in similar functional forms but with opposite signs in quantity and price monopoly settings. If quantity is the firm's choice variable, risk aversion tends to reduce competiveness. In contrast, if the firm chooses price, risk aversion tends to increase competiveness.

The impact of risk aversion is more complex in oligopoly due to strategic interaction. We will deal with this issue below.

\section{Oligopoly}

Based on the insights derived in the case of monopoly, we will examine the impact of risk aversion in Cournot and Bertrand oligopolies in this section. The Cournot model will resemble the case of a quantity-setting monopolist, while the Bertrand model follows the case of price setting. The effects of risk aversion will be qualitatively similar to the corresponding monopoly cases, but their magnitudes will be affected by strategic considerations. With limited information, firms cannot choose the equilibrium strategy based on the knowledge of risk aversion and other information. We present a simple and naïve decision rule, similar to that in the monopoly case, under which play converges to the equilibrium gradually. We evaluate the impacts of the risk aversion parameters $\delta_{i}$ on outputs, prices, consumer surplus and social welfare. Given the firms' 
asymmetry in demand, costs and risk attitude, we cannot obtain clear-cut solutions as in the monopoly case. Nonetheless we will express the impacts of risk aversion via potentially observable variables, rather than unobservable risk aversion. Without loss of generality, we consider the impacts of firm 1's risk aversion $\delta_{1}$, and show that they are closely linked to the corresponding effects of its cost changes.

\subsection{Cournot oligopoly}

The literature has shown that both monopoly and duopoly markets become less competitive when firms face uncertain prices and choose quantities. We will evaluate the impact of a firm's risk aversion quantitatively in an asymmetric Cournot oligopoly. We assume that each firm $i$ chooses its output $x_{i t}$ in period $t$ to maximize its meanvariance utility $x_{i t} E\left(p_{i t}-c_{i}\right)-\delta_{i} \sigma_{i}^{2} x_{i t}^{2}$, without knowing rivals' risk aversion as well as their demand and cost conditions. The first-order condition for $x_{i t}$ is

$$
E\left(p_{i t}\right)-c_{i}-b_{i i} x_{i t}-2 \delta_{i} \sigma_{i}^{2} x_{i t}=0 \text { for all } i
$$

Its optimal output $x_{i t}$ should depend on its price expectation $E\left(p_{i t}\right)$. However, unable to anticipate rivals' decisions, its best price estimate is to adjust its previous price by its own output change, i.e. $E\left(p_{i t}\right)=p_{i t-1}-b_{i i}\left(x_{i t}-x_{i t-1}\right)$. Substituting this into (4), we have $p_{i t-1}-b_{i i}\left(x_{i t}-x_{i t-1}\right)-c_{i}-b_{i i} x_{i t}-2 \delta_{i} \sigma_{i}^{2} x_{i t}=0$. So the optimal output is

$$
x_{i t}=\frac{p_{i t-1}-c_{i}+b_{i i} x_{i t-1}}{2\left(b_{i i}+\delta_{i} \sigma_{i}^{2}\right)} \text { for all } i
$$

When every firm follows (5), it is not guaranteed that the output is truly optimal immediately as in the monopoly case. As firms adjust outputs in each period, the market may converge. The equilibrium is defined as a steady state where each firm repeats its decision, i.e. $x_{i t}=x_{i t-1}$ and its price expectation is realized, i.e. $E\left(p_{i t}\right)=p_{i t}$. We denote firm $i$ 's equilibrium output and price by $x_{i}$ and $p_{i}$. Then (4) becomes:

$$
\left(b_{i i}+2 \delta_{i} \sigma_{i}^{2}\right) x_{i}=a_{i}-\sum_{j=1}^{n} b_{i j} x_{j}-c_{i} \text { for all } i
$$

In fact Eq. (6) is identical to the Cournot-Nash equilibrium condition with complete information. So our steady state coincides with the Nash equilibrium, but is obtained through quantity adjustments with realistic limited information, not by rational anticipation of rivals' actions. We can write (6) as $\boldsymbol{H} \boldsymbol{x}=\boldsymbol{a}-\boldsymbol{B} \boldsymbol{x}-\boldsymbol{c}$, where $\boldsymbol{H}$ is an $n \times n$ diagonal matrix whose $i$-th diagonal element $h_{i i}=b_{i i}+2 \delta_{i} \sigma_{i}^{2}$. As $\boldsymbol{H}+\boldsymbol{B}$ is positive definite and its inverse exists, we can solve the Cournot equilibrium output vector as:

$$
\boldsymbol{x}=(\boldsymbol{H}+\boldsymbol{B})^{-1}(\boldsymbol{a}-\boldsymbol{c})
$$

Now we examine how $\delta_{1}$ affects the equilibrium outputs and prices. We try to express these effects via observable variables, rather than unobservable risk aversion. 
When $\delta_{1}$ changes, firm 1 will first adjust $x_{1}$ according to (5). This will affect other firms' prices and cause their responses. A new equilibrium will be reached through this process of output adjustments. We examine how the final outcome determined by (7) responds to the change in $\delta_{1}$. In an asymmetric oligopoly, the responses $\frac{\partial x_{i}}{\partial \delta_{1}}$ and $\frac{\partial p_{i}}{\partial \delta_{1}}$ are rather complex. Nonetheless we can express them via potentially observable variables, such as firm $i$ 's output and price responses to firm 1's cost $c_{1}, \frac{\partial x_{i}}{\partial c_{1}}$ and $\frac{\partial p_{i}}{\partial c_{1}}$.

Proposition 3 In a Cournot oligopoly the effects of firm 1's risk aversion on each firm's output and price are:

$$
\frac{\partial x_{i}}{\partial \delta_{1}}=2 \frac{V\left(\pi_{1}\right)}{x_{1}} \quad \frac{\partial x_{i}}{\partial c_{1}}, \quad \frac{\partial p_{i}}{\partial \delta_{1}}=2 \frac{V\left(\pi_{1}\right)}{x_{1}} \frac{\partial p_{i}}{\partial c_{1}} .
$$

Proof See "Appendix 3".

So the impact of $\delta_{1}$ on every firm's output and price is proportional to the output and price responses to firm 1's cost change, and its profit variance per output unit. These are observable variables and can potentially be estimated with data, unlike the unobservable risk aversion parameter. Using Eq. (7), we can see that $-\frac{\partial x_{i}}{\partial c_{1}}$ is equal to the $i$-th element of the first row in $(\boldsymbol{H}+\boldsymbol{B})^{-1}$. From (6) we see $p_{i}=c_{i}+h_{i i} x_{i}$. So we have $\frac{\partial p_{1}}{\partial c_{1}}=1+h_{11} \frac{\partial x_{1}}{\partial c_{1}}$ and $\frac{\partial p_{i}}{\partial c_{1}}=h_{i i} \frac{\partial x_{i}}{\partial c_{1}}$ for $i \neq 1$. Moreover, from (7) we can determine the signs of $\frac{\partial x_{1}}{\partial c_{1}}$ and $\frac{\partial p_{1}}{\partial c_{1}}$. Since matrix $(\boldsymbol{H}+\boldsymbol{B})^{-1}$ is positive definite, its diagonal elements are positive, so we have $\frac{\partial x_{1}}{\partial c_{1}}<0$. It can also be shown that we always have $\frac{\partial p_{1}}{\partial c_{1}}>0$. We cannot determine the sign of $\frac{\partial x_{i}}{\partial c_{1}}$ for $i \neq 1$ in general, but if goods are complements, we have $\frac{\partial x_{i}}{\partial c_{1}}<0$.

Given Proposition 3, we evaluate the impact of $\delta_{1}$ on consumer surplus $(C S)$ and social welfare $(S W)$. The latter is the sum of consumer surplus and total profit of all firms, i.e. $S W=u-\boldsymbol{c}^{\prime} \boldsymbol{x}-x_{0}=(\boldsymbol{a}-\boldsymbol{c})^{\prime} \boldsymbol{x}-0.5 \boldsymbol{x}^{\prime} \boldsymbol{B} \boldsymbol{x}$. Consumer surplus is $u-\boldsymbol{p}^{\prime} \boldsymbol{x}-x_{0}$. As $\boldsymbol{p}=\boldsymbol{a}-\boldsymbol{B} \boldsymbol{x}$, we have $C S=0.5 \boldsymbol{x} \boldsymbol{B} \boldsymbol{x}$. Although both are complex functions in asymmetric Cournot oligopoly, we can again express the welfare effects of risk aversion via observable variables. Similar to the impact on outputs and prices, the welfare effects are proportional to $\frac{V\left(\pi_{1}\right)}{x_{1}}$, and also depend on the effect of firm 1's cost on the total profit, i.e. $\frac{\partial \pi}{\partial c_{1}}$.

Proposition 4 In a Cournot oligopoly the effects of firm 1's risk aversion on social welfare and consumer surplus are:

$$
\frac{\partial S W}{\partial \delta_{1}}=\frac{V\left(\pi_{1}\right)}{x_{1}} \frac{\partial \pi}{\partial c_{1}}, \quad \frac{\partial C S}{\partial \delta_{1}}=-V\left(\pi_{1}\right)\left(2+\frac{1}{x_{1}} \frac{\partial \pi}{\partial c_{1}}\right) .
$$

Proof See "Appendix 4".

If we know how firm 1's cost affects total profit, we can estimate the welfare effect of $\delta_{1}$. When $c_{1}$ rises, the direct impact on $\pi$ is $-x_{1}$, only affecting firm 1 . Then firm 1 will adjust its output according to (5), and other firms will follow. Usually the total profit falls when $c_{1}$ rises, and the welfare effect is negative. Consumers are 
usually worse off since it is likely that $\frac{\partial \pi}{\partial c_{1}}>-2 x_{1}$. Proposition 4 also implies that $\frac{\partial \pi}{\partial \delta_{1}}=\frac{\partial S W}{\partial \delta_{1}}-\frac{\partial C S}{\partial \delta_{1}}=2 V\left(\pi_{1}\right)\left(1+\frac{1}{x_{1}} \frac{\partial \pi}{\partial c_{1}}\right)$, which is negative if and only if $\frac{\partial \pi}{\partial c_{1}}<-x_{1}$. Furthermore we can find the impact of $\delta_{1}$ on the sum of social welfare and consumer surplus. Adding the effects on social welfare and consumer surplus together we get:

Corollary 1 In a Cournot oligopoly the effect of firm 1's risk aversion on the sum of social welfare and consumer surplus is: $\frac{\partial S W}{\partial \delta_{1}}+\frac{\partial C S}{\partial \delta_{1}}=-2 V\left(\pi_{1}\right)$.

Similar to the quantity setting monopoly case, risk aversion always decreases the sum of social welfare and consumer surplus, by twice the profit variance. This result indicates a lower competitiveness of the oligopoly market. ${ }^{5}$ Both social welfare and consumer surplus are widely used in antitrust and competition policies, as well as in broader contexts. Equivalently, as the sum is equal to $(\boldsymbol{a}-\boldsymbol{c})^{\prime} \boldsymbol{x}$, we may view it as a measure of total output, weighted by vector $\boldsymbol{a}-\boldsymbol{c}$. In this sense, risk aversion always has a negative and precise effect on competitiveness in an asymmetric Cournot oligopoly.

\subsection{Bertrand oligopoly}

The literature has shown that both monopoly and duopoly markets become more competitive when firms face uncertain demands and choose prices. We will quantitatively evaluate the impact of a firm's risk aversion in an asymmetric Bertrand oligopoly. Given an uncertain quantity demanded, a Bertrand firm's mean-variance utility function in period $t$ is equal to $\left(p_{i t}-c_{i}\right) E\left(x_{i t}\right)-\delta_{i} \rho_{i}^{2}\left(p_{i t}-c_{i}\right)^{2}$. When a firm chooses its price $p_{i t}$ to maximize this utility, the first-order condition for the optimal price is:

$$
E\left(x_{i t}\right)-\beta_{i i}\left(p_{i t}-c_{i}\right)-2 \delta_{i} \rho_{i}^{2}\left(p_{i}-c_{i}\right)=0 \text { for all } i
$$

Similar to the Cournot case, we assume each firm cannot anticipate other firms' decisions and does not know its own demand function except for the slope. Each firm can only estimate its quantity demanded $x_{i t}$ based on the previous quantity $x_{i t-1}$ and its own price change from the last period, i.e. $E\left(x_{i t}\right)=x_{i t-1}-\beta_{i i}\left(p_{i t}-p_{i t-1}\right)$. Substituting this into the first-order condition (8), we can solve for the optimal naïve price strategy 6

$$
p_{i t}=c_{i}+\frac{x_{i t-1}+\beta_{i i}\left(p_{i t-1}-c_{i}\right)}{2\left(\beta_{i i}+\delta_{\mathrm{i}} \rho_{i}^{2}\right)} \text { for all } i
$$

As in the Cournot case, the equilibrium is defined as a steady state where each firm repeats its price, i.e. $p_{i t}=p_{i t-1}$ and its quantity expectation is realized, i.e. $E\left(x_{i t}\right)=x_{i t}$. We denote the equilibrium price and output by $p_{i}$ and $x_{i}$. So (8) becomes:

\footnotetext{
5 When comparing Cournot and Bertrand oligopolies, Amir and Jin (2001) use the sum of consumer surplus and social welfare to indicate market competitiveness.

6 This pricing rule is similar to that used in Jin (2001) except for the risk aversion, and will converge to the Bertrand-Nash equilibrium under reasonable conditions.
} 


$$
\left(\beta_{i i}+2 \delta_{\mathrm{i}} \rho_{i}^{2}\right)\left(p_{i}-c_{i}\right)=x_{i} \quad \text { for all } i
$$

Equation (10) is again identical to the Bertrand-Nash equilibrium condition with complete information. Our steady state coincides with the Bertrand equilibrium but is obtained through price adjustments with limited information, not by rational anticipation of rivals' actions. We can write (10) as $\boldsymbol{p}-\boldsymbol{c}=\boldsymbol{G} \boldsymbol{x}$, where $\boldsymbol{G}$ is an $n \times n$ diagonal matrix whose $i$-th diagonal element $g_{i i}=\frac{1}{\beta_{i i}+2 \delta_{i} \rho_{i}^{2}}$. As $\boldsymbol{p}=\boldsymbol{a}-\boldsymbol{B} \boldsymbol{x}$, we have $\boldsymbol{G} \boldsymbol{x}=\boldsymbol{a}-\boldsymbol{B} \boldsymbol{x}-\boldsymbol{c}$. As $\boldsymbol{G}+\boldsymbol{B}$ is positive definite, the Bertrand equilibrium price can be solved as

$$
\boldsymbol{x}=(\boldsymbol{G}+\boldsymbol{B})^{-1}(\boldsymbol{a}-\boldsymbol{c})
$$

When $\delta_{1}$ changes, firm 1 will first adjust $p_{1}$ according to (9). This will cause other firms' responses and a new equilibrium will be reached through the adjustment process. Given (11) we can evaluate the impact of $\delta_{1}$ on outputs and prices. Equation (11) has the same form as (7) except for $\boldsymbol{G}$ replacing $\boldsymbol{H}$. Similar to the Cournot case, we can express these impacts via observable variables, such as output and price responses to a change in $c_{1}$, i.e. $\frac{\partial x_{i}}{\partial c_{1}}, \frac{\partial p_{i}}{\partial c_{1}}$ and $\frac{V\left(\pi_{1}\right)}{x_{1}}$. The only major difference between Cournot and Bertrand oligopolies is the opposite signs (see "Appendix 5").

Proposition 5 In a Bertrand oligopoly the effects of firm 1's risk aversion on each firm's output and price are respectively

$$
\frac{\partial x_{i}}{\partial \delta_{1}}=-2 \frac{V\left(\pi_{1}\right)}{x_{1}} \frac{\partial x_{i}}{\partial c_{1}}, \quad \frac{\partial p_{i}}{\partial \delta_{1}}=-2 \frac{V\left(\pi_{1}\right)}{x_{1}} \frac{\partial p_{i}}{\partial c_{1}} .
$$

Here we obtain almost opposite results to the Cournot case. However the magnitude of $\frac{\partial x_{i}}{\partial c_{1}}$ differs from that in Cournot oligopoly. From (11) we see that $-\frac{\partial x_{i}}{\partial c_{1}}$ is equal to the $i$-th element of the first row in $(\boldsymbol{G}+\boldsymbol{B})^{-1}$. It follows from (10) that $p_{i}=c_{i}+g_{i i} x_{i}$. So we get $\frac{\partial p_{1}}{\partial c_{1}}=1+g_{11} \frac{\partial x_{1}}{\partial c_{1}}$ and $\frac{\partial p_{i}}{\partial c_{1}}=g_{i i} \frac{\partial x_{i}}{\partial c_{1}}$ for $i \neq 1$. Moreover we always have $\frac{\partial x_{i}}{\partial c_{1}}<0$ as matrix $\boldsymbol{G}+\boldsymbol{B}$ is positive definite. Likewise we have $\frac{\partial p_{1}}{\partial c_{1}}>0$. If all goods are substitutes, we can show that $\frac{\partial p_{i}}{\partial c_{1}}>0$. In a symmetric case, $\frac{\partial x_{i}}{\partial c_{1}}$ and $\frac{\partial p_{i}}{\partial c_{1}}$ must have the same signs in both Cournot and Bertrand cases despite their difference in magnitude. This implies opposite signs for $\frac{\partial x_{i}}{\partial \delta_{1}}$ and $\frac{\partial p_{i}}{\partial \delta_{1}}$ under quantity and price competition. This contrast between Cournot and Bertrand cases extends the findings in the earlier literature.

Given Proposition 5, the impacts of a firm's risk aversion on social welfare and consumer surplus in Bertrand oligopoly are also similar to those in Cournot oligopoly. The proof is essentially identical to the Cournot case except for replacing matrix $\boldsymbol{H}$ by $\boldsymbol{G}$, and Eq. (7) by (11). The only difference is the opposite signs, obtained in Proposition 6, in comparison to those in Proposition 4.

Proposition 6 In a Bertrand oligopoly, the effects of firm 1's risk aversion on social welfare and consumer surplus are respectively

$$
\frac{\partial S W}{\partial \delta_{1}}=-\frac{V\left(\pi_{1}\right)}{x_{1}} \frac{\partial \pi}{\partial c_{1}}, \quad \frac{\partial C S}{\partial \delta_{1}}=V\left(\pi_{1}\right)\left(2+\frac{1}{x_{1}} \frac{\partial \pi}{\partial c_{1}}\right) .
$$


Similar to the Cournot case, when $c_{1}$ changes, the direct impact on $\pi$ is $-x_{1}$, only affecting firm 1 . Then firm 1 will adjust its price according to (9), and other firms will follow. The welfare effect is likely to be positive since the total profit usually falls with $c_{1}$. Consumers are likely to be better off as $\frac{\partial \pi}{\partial c_{1}}>-2 x_{1}$ usually. From Proposition 6 we also obtain $\frac{\partial \pi}{\partial \delta_{1}}=-2 V\left(\pi_{1}\right)\left(1+\frac{1}{x_{1}} \frac{\partial \pi}{\partial c_{1}}\right)$, which is negative if and only if $\frac{\partial \pi}{\partial c_{1}}>-x_{1}$. A similar effect on the sum of consumer surplus and social welfare in the Cournot case also applies.

Corollary 2 In a Bertrand oligopoly the effect of firm 1's risk aversion on the sum of social welfare and consumer surplus is: $\frac{\partial S W}{\partial \delta_{1}}+\frac{\partial C S}{\partial \delta_{1}}=2 V\left(\pi_{1}\right)$.

Opposite to the Cournot case and similar to the price setting monopoly, risk aversion tends to make the market more competitive, and always raises the sum of consumer surplus and social welfare. Here we see a strong contrast between asymmetric Cournot and Bertrand oligopolies, as the literature found in symmetric cases. Furthermore, we may consider the risk factor $\delta_{1} V\left(\pi_{1}\right)$ denoted by $r_{1}$. A change in $r_{1}$ is equal to a change in $\delta_{1}$ multiplied by $V\left(\pi_{1}\right)$. Then Corollaries 1 and 2 can be written as $\frac{\partial S W}{\partial r_{1}}+\frac{\partial C S}{\partial r_{1}}=-2$ and 2 in Cournot and Bertrand oligopolies respectively.

At this stage it is appropriate to compare and distinguish the differences due to market structure (oligopoly and monopoly) and those due to quantity setting versus price setting. Since the quantity (price) setting monopoly is a special case of our Cournot (Bertrand) oligopoly, so is the result. The impact of risk aversion is qualitatively different when firms choose quantities or prices, as shown by the opposite signs. While these opposite impacts in the quantity and price setting monopolies are carried over to the more complicated Cournot and Bertrand oligopolies, the similar expressions such as $\frac{\partial x_{i}}{\partial c_{1}}$ and $\frac{\partial p_{i}}{\partial c_{1}}$ have different values due to strategic interaction in oligopolies. They are also different in Cournot and Bertrand competition due to different strategic interactions.

In spite of the different magnitudes of the impacts of risk aversion, it is surprising that we obtain almost identical expressions for these impacts. This fact allows us to design a relatively simple tax policy to reduce or eliminate the undesirable effects of risk aversion. Next we show how tax policy may counterbalance the effect of risk aversion.

\section{Countervailing taxes}

In the previous sections we focus on the impact of risk aversion on market competitiveness. On the other hand risk aversion affects firms' bankruptcy risk due to their behavioral changes as mentioned in the introduction. In Cournot oligopoly, these two effects work against each other. More risk aversion on the part of firms makes the market less competitive but less risky; while less risk aversion makes the market more competitive but riskier. In Bertrand oligopoly the two effects move together. More risk aversion increases the competiveness and reduces the risk, while less risk aversion would reduce competitiveness and also raise the risk. Hence a tax policy may be needed to correct undesirable effects of risk aversion in both markets. In this section we will use our earlier results to obtain these countervailing taxes in Cournot and 
Bertrand oligopolies, which also applies to the cases of a quantity or price setting monopoly.

Given previous results, we see that the impact of a firm's risk aversion can be expressed as a change in its cost. We assume the current cost $c_{1}$ includes a unit tax. Then a cost change can be caused by a tax change. In Cournot oligopoly, an increase in $\delta_{1}$ is equivalent to a certain increase in $c_{1}$. This cost change can be offset by the same amount of tax reduction on firm 1's product. Hence, the impact of risk aversion can be offset by an equivalent tax change. This simple relation can be explained more accurately by our equilibrium condition (6) for $i=1$. With $\Delta \delta_{1}>0$, the left hand side of (6) rises by $2 \sigma_{1}^{2} x_{1} \Delta \delta_{1}$. If we reduce the tax (hence lower $c_{1}$ ) by $2 \frac{V\left(\pi_{1}\right)}{x_{1}} \Delta \delta_{1}$ on the right hand side, (6) remains valid and the equilibrium will not change. Hence a tax reduction of $\Delta t_{1}=-2 \frac{V\left(\pi_{1}\right)}{x_{1}} \Delta \delta_{1}$ can exactly cancel the change of risk aversion $\Delta \delta_{1}>0$.

In Bertrand oligopoly, the impact of a decrease in $\delta_{1}$ is equivalent to a certain rise in $c_{1}$. To eliminate the impact of $\Delta \delta_{1}<0$, we should again lower the unit tax. This can be seen in our equilibrium condition (10) for $i=1$. With $\Delta \delta_{1}<0$, the left hand side of (10) falls by $2 \rho_{1}^{2}\left(p_{1}-c_{1}\right) \Delta \delta_{1}$. If we lower $c_{1}$ by a tax reduction of $\Delta t_{1}$, the left hand side will rise by $-\left(\beta_{11}+2 \delta_{1} \rho_{1}^{2}\right) \Delta t_{1}$. When $\left(\beta_{11}+2 \delta_{1} \rho_{1}^{2}\right) \Delta t_{1}=2 \rho_{1}^{2}\left(p_{1}-c_{1}\right) \Delta \delta_{1}$, these two effects will cancel each other out, and (10) will remain valid, so the equilibrium will not change. Using (10) we get $\Delta t_{1}=2 \frac{\rho_{1}^{2}\left(p_{1}-c_{1}\right)^{2}}{x_{1}} \Delta \delta_{1}=2 \frac{V\left(\pi_{1}\right)}{x_{1}} \Delta \delta_{1}$. This is the countervailing tax reduction to $\Delta \delta_{1}<0$ in Bertrand oligopoly.

Proposition 7 To eliminate the impact of $\Delta \delta_{1}>(<) 0$ in Cournot (Bertrand) oligopoly, we should reduce unit tax on firm l's product by $2 \frac{V\left(\pi_{1}\right)}{x_{1}} \Delta \delta_{1}$.

As we have shown, the countervailing tax for firm 1's risk aversion cancels out its incentive distortion, without direct impacts on other firms. If other firms' risk aversion also changes, the only thing we need to do is to adjust taxes on their products. This simple tax rule is independent of how products are related, i.e., whether they are substitutes or complements. It is thus feasible to reduce or eliminate the undesirable impacts of risk aversion even in complicated Cournot and Bertrand markets.

\section{Concluding remarks}

In this paper we quantitatively evaluate the impact of a firm's risk aversion on outputs, prices, consumer surplus and social welfare. We can quantitatively estimate these effects based on observable variables, excluding unobservable risk aversion. In particular, these impacts are closely linked to the effects of a firm's cost change. Thus suitable tax policy may offset these effects by changing firms' costs. We suggest countervailing unit taxes to eliminate the undesirable effects of risk aversion.

Hopefully these findings can enhance our understanding of the impact of risk aversion, especially the distinction between Cournot and Bertrand markets. For instance, one can argue that an inter-bank loan market is close to a Cournot oligopoly, as banks offer homogeneous goods and face severe competition. Consequently they can hardly choose their interest rates, but only choose quantities of their loans. In this case an 
increase of banks' risk aversion will reduce the amount of loans offered and push the interest rate up. On the other hand, competition among supermarkets may constitute the opposite case, where sellers choose prices and consumers decide how much to buy, as in a Bertrand oligopoly. Less risk aversion will raise prices, reduce market competiveness and also raise the bankruptcy risk. In these cases we may need policy intervention to eliminate undesirable impacts and maintain a balance between market efficiency and stability. Our findings may also provide support for the Tobin tax. For instance, when financial managers become less risk averse, loan quantities tend to increase and default risk rises. If the government raises a Tobin tax as the countervailing measure, over-speculation may be prevented.

While the advantage of this paper is to allow arbitrary product relations and any number of firms, its lack of generality is to restrict demand and cost functions to be linear and to postulate firms' utility functions to be of the mean-variance type. These assumptions allow us to solve the equilibrium prices and outputs explicitly and thereby derive precise quantitative insights. When firms' utility functions are more complex, or demand and cost functions are nonlinear, closed-form solutions are generally not obtainable. If these functions are relatively smooth, our linear models can serve as approximations, and the results presented here may end up close to the true optimal solutions. But this may not apply to highly nonlinear functions. Further research may reveal the extent to which the conclusions derived here can be extended to these cases.

Open Access This article is distributed under the terms of the Creative Commons Attribution 4.0 International License (http://creativecommons.org/licenses/by/4.0/), which permits unrestricted use, distribution, and reproduction in any medium, provided you give appropriate credit to the original author(s) and the source, provide a link to the Creative Commons license, and indicate if changes were made.

\section{Appendix 1 (Proof for Proposition 1)}

Differentiating $S W+C S=(\boldsymbol{a}-\boldsymbol{c})^{\prime} \boldsymbol{x}$ we obtain $\frac{\partial(S W+C S)}{\partial \delta}=(\boldsymbol{a}-\boldsymbol{c})^{\prime} \frac{\partial x}{\partial \delta}$.

To find $\frac{\partial x}{\partial \delta}$ given $\boldsymbol{x}=0.5(\boldsymbol{B}+\delta \boldsymbol{\Sigma})^{-1}(\boldsymbol{a}-\boldsymbol{c})$, we first write

$$
\begin{aligned}
& {[\boldsymbol{B}+(\delta+\Delta \delta) \boldsymbol{\Sigma}]^{-1}-(\boldsymbol{B}+\delta \boldsymbol{\Sigma})^{-1}} \\
& \quad=[\boldsymbol{B}+(\delta+\Delta \delta) \boldsymbol{\Sigma}]^{-1}[\boldsymbol{B}+\delta \boldsymbol{\Sigma}-\boldsymbol{B}-(\delta+\Delta \delta) \boldsymbol{\Sigma}](\boldsymbol{B}+\delta \boldsymbol{\Sigma})^{-1} \\
& \quad=-[\boldsymbol{B}+(\delta+\Delta \delta) \boldsymbol{\Sigma}]^{-1} \Delta \delta \boldsymbol{\Sigma}(\boldsymbol{B}+\delta \boldsymbol{\Sigma})^{-1}
\end{aligned}
$$

Divide it by $\Delta \delta$ and let $\Delta \delta \rightarrow 0$, we then obtain

$$
\frac{\partial x}{\partial \delta}=-0.5(B+\delta \boldsymbol{\Sigma})^{-1} \boldsymbol{\Sigma}(\boldsymbol{B}+\delta \boldsymbol{\Sigma})^{-1}(\boldsymbol{a}-\boldsymbol{c})=-(\boldsymbol{B}+\delta \boldsymbol{\Sigma})^{-1} \boldsymbol{\Sigma} \boldsymbol{x}
$$

So $\frac{\partial(S W+C S)}{\partial \delta}=(\boldsymbol{a}-\boldsymbol{c})^{\prime} \frac{\partial x}{\partial \delta}=-(\boldsymbol{a}-\boldsymbol{c})^{\prime}(\boldsymbol{B}+\delta \boldsymbol{\Sigma})^{-1} \boldsymbol{\Sigma} \boldsymbol{x}=-2 \boldsymbol{x}^{\prime} \boldsymbol{\Sigma} \boldsymbol{x}=-2 V(\pi)$. 


\section{Appendix 2 (Proof for Proposition 2)}

As $\boldsymbol{x}=\boldsymbol{B}^{-1}(\boldsymbol{a}-\boldsymbol{p}), \frac{\partial x}{\partial \delta}=-\boldsymbol{B}^{-1} \frac{\partial p}{\partial \delta}$, we have $\frac{\partial(S W+C S)}{\partial \delta}=(\boldsymbol{a}-\boldsymbol{c})^{\prime} \frac{\partial x}{\partial \delta}$ $=-(\boldsymbol{a}-\boldsymbol{c})^{\prime} \boldsymbol{B}^{-1} \frac{\partial p}{\partial \delta}$.

Given $\boldsymbol{p}=\boldsymbol{c}+0.5(\boldsymbol{I}+\delta \boldsymbol{B} \boldsymbol{\Omega})^{-1}(\boldsymbol{a}-\boldsymbol{c})$, we write

$$
\begin{aligned}
& {\left[\begin{array}{l}
\boldsymbol{I} \\
+
\end{array} \quad(\delta+\Delta \delta) \boldsymbol{B} \boldsymbol{\Omega}\right]^{-1}-(\boldsymbol{I}+\delta \boldsymbol{B} \boldsymbol{\Omega})^{-1}} \\
& \quad=[\boldsymbol{I}+(\delta+\Delta \delta) \boldsymbol{B} \boldsymbol{\Omega}]^{-1}[\boldsymbol{I}+\delta \boldsymbol{B} \boldsymbol{\Omega}-\boldsymbol{I}-(\delta+\Delta \delta) \boldsymbol{B} \boldsymbol{\Omega}](\boldsymbol{I}+\delta \boldsymbol{B} \boldsymbol{\Omega})^{-1} \\
& \quad=-[\boldsymbol{I}+(\delta+\Delta \delta) \boldsymbol{B} \boldsymbol{\Omega}]^{-1} \Delta \delta \boldsymbol{B} \boldsymbol{\Omega}(\boldsymbol{I}+\delta \boldsymbol{B} \boldsymbol{\Omega})^{-1}
\end{aligned}
$$

Divide it by $\Delta \delta$ and let $\Delta \delta \rightarrow 0$, we have $\frac{\partial p}{\partial \delta}=-0.5(\boldsymbol{I}+\delta \mathbf{B} \boldsymbol{\Omega})^{-1} \boldsymbol{B} \boldsymbol{\Omega}(\boldsymbol{I}+\delta \boldsymbol{B} \boldsymbol{\Omega})^{-1}(\boldsymbol{a}-$ $\boldsymbol{c})=-(\boldsymbol{I}+\delta \boldsymbol{B} \boldsymbol{\Omega})^{-1} \boldsymbol{B} \boldsymbol{\Omega}(\boldsymbol{p}-\boldsymbol{c})$. Hence we find

$$
\begin{aligned}
& \frac{\partial(S W+C S)}{\partial \delta}=(\boldsymbol{a}-\boldsymbol{c})^{\prime} \frac{\partial x}{\partial \delta}=(\boldsymbol{a}-\boldsymbol{c})^{\prime} \boldsymbol{B}^{-1}(\boldsymbol{I}+\delta \boldsymbol{B} \boldsymbol{\Omega})^{-1} \boldsymbol{B} \boldsymbol{\Omega}(\boldsymbol{p}-\boldsymbol{c}) \\
& \quad=(\boldsymbol{a}-\boldsymbol{c})^{\prime}(\boldsymbol{B}+\delta \boldsymbol{B} \boldsymbol{\Omega} \boldsymbol{B})^{-1} \boldsymbol{B} \boldsymbol{\Omega}(\boldsymbol{p}-\boldsymbol{c})=(\boldsymbol{a}-\boldsymbol{c})^{\prime}(\boldsymbol{I}+\delta \boldsymbol{\Omega} \boldsymbol{B})^{-1} \boldsymbol{\Omega}(\boldsymbol{p}-\boldsymbol{c}) \\
& =2(\boldsymbol{p}-\boldsymbol{c})^{\prime} \boldsymbol{\Omega}(\boldsymbol{p}-\boldsymbol{c})=2 V(\pi) .
\end{aligned}
$$

\section{Appendix 3 (Proof for Proposition 3)}

We write the Eq. (6) as $(\boldsymbol{B}+\boldsymbol{H}) \boldsymbol{x}=\boldsymbol{a}-\boldsymbol{c}$. Differentiate it with respect to $\delta_{1}$. The derivative of $\boldsymbol{B}+\boldsymbol{H}$ is zero except for the first diagonal of $2 \sigma_{1}^{2}$. Let $\boldsymbol{\iota}$ be an $\mathrm{n} \times 1$ vector with all elements 0 except for the $1^{\text {st }}$ being 1 . So we have $2 \sigma_{1}^{2} x_{1} \iota+(\boldsymbol{B}+\boldsymbol{H}) \frac{\partial x}{\partial \delta_{1}}=\mathbf{0}$.

Hence we find $\frac{\partial x}{\partial \delta_{1}}=-2 \sigma_{1}^{2} x_{1}(\boldsymbol{B}+\boldsymbol{H})^{-1} \iota=-2 \sigma_{1}^{2} x_{1}(\boldsymbol{B}+\boldsymbol{H})_{1}^{-1}$.

From (7), we have $-(\boldsymbol{B}+\boldsymbol{H})_{1}^{-1}=\frac{\partial x}{\partial c_{1}}$. So we obtain $\frac{\partial x}{\partial \delta_{1}}=2 \sigma_{1}^{2} x_{1} \frac{\partial x}{\partial c_{1}}=2 \frac{V\left(\pi_{1}\right)}{x_{1}} \frac{\partial x}{\partial c_{1}}$.

Given $\boldsymbol{p}=\boldsymbol{a}-\boldsymbol{B} \boldsymbol{x}$, we have $\frac{\partial p}{\partial \delta_{1}}=-\boldsymbol{B} \frac{\partial x}{\partial \delta_{1}}$. Moreover, since we have $\frac{\partial p}{\partial c_{1}}=-\boldsymbol{B} \frac{\partial x}{\partial c_{1}}$ and $\frac{\partial x}{\partial \delta_{1}}=2 \frac{V\left(\pi_{1}\right)}{x_{1}} \frac{\partial x}{\partial c_{1}}$, we obtain $\frac{\partial p}{\partial \delta_{1}}=-2 \frac{V\left(\pi_{1}\right)}{x_{1}} \boldsymbol{B} \frac{\partial x}{\partial c_{1}}=2 \frac{V\left(\pi_{1}\right)}{x_{1}} \frac{\partial p}{\partial c_{1}}$.

\section{Appendix 4 (Proof for Proposition 4)}

Differentiate $S W=(\boldsymbol{a}-\boldsymbol{c})^{\prime} \boldsymbol{x}-0.5 \boldsymbol{x}^{\prime} \boldsymbol{B} \boldsymbol{x}$ with respect to $\delta_{1}$, we get $\frac{\partial S W}{\partial \delta_{1}}=(\boldsymbol{a}-\boldsymbol{c}-$ $\boldsymbol{B} \boldsymbol{x})^{\prime} \frac{\partial x}{\partial \delta_{1}}$. Since $\boldsymbol{B} \boldsymbol{x}=\boldsymbol{a}-\boldsymbol{p}$, we have $\frac{\partial S W}{\partial \delta_{1}}=(\boldsymbol{p}-\boldsymbol{c})^{\prime} \frac{\partial x}{\partial \delta_{1}}=2 \frac{V\left(\pi_{1}\right)}{x_{1}}(\boldsymbol{p}-\boldsymbol{c})^{\prime} \frac{\partial x}{\partial c_{1}}$.

Now we need to show that $2(\boldsymbol{p}-\boldsymbol{c})^{\prime} \frac{\partial x}{\partial c_{1}}=\frac{\partial \pi}{\partial c_{1}}$.

As $\pi=(\boldsymbol{p}-\boldsymbol{c})^{\prime} \boldsymbol{x}$ and $\boldsymbol{p}=\boldsymbol{a}-\boldsymbol{B} \boldsymbol{x}, \frac{\partial \pi}{\partial c_{1}}=(\boldsymbol{p}-\boldsymbol{c}-\boldsymbol{B} \boldsymbol{x})^{\prime} \frac{\partial x}{\partial c_{1}}-x_{1}=(2 \boldsymbol{p}-\boldsymbol{c}-\boldsymbol{a})^{\prime} \frac{\partial x}{\partial c_{1}}-x_{1}$.

It suffices to show $(\boldsymbol{c}-\boldsymbol{a})^{\prime} \frac{\partial x}{\partial c_{1}}=x_{1}$. This holds as (7) implies $\frac{\partial x}{\partial c_{1}}=-(\boldsymbol{B}+\boldsymbol{H})_{1}^{-1}$.

Hence we have $2(\boldsymbol{p}-\boldsymbol{c})^{\prime} \frac{\partial x}{\partial c_{1}}=\frac{\partial \pi}{\partial c_{1}}$, and thus $\frac{\partial S W}{\partial \delta_{1}}=\frac{V\left(\pi_{1}\right)}{x_{1}} \frac{\partial \pi}{\partial c_{1}}$.

Then we write $C S$ as $0.5 \boldsymbol{x}^{\prime} \boldsymbol{B} \boldsymbol{x}=(\boldsymbol{a}-\boldsymbol{c})^{\prime} \boldsymbol{x}-S W$. So $\frac{\partial C S}{\partial \delta_{1}}=(\boldsymbol{a}-\boldsymbol{c})^{\prime} \frac{\partial x}{\partial \delta_{1}}-\frac{\partial S W}{\partial \delta_{1}}$. As $\frac{\partial x}{\partial \delta_{1}}=2 \frac{V\left(\pi_{1}\right)}{x_{1}} \frac{\partial x}{\partial c_{1}}$ and $(\boldsymbol{c}-\boldsymbol{a})^{\prime} \frac{\partial x}{\partial c_{1}}=x_{1}, \frac{\partial C S}{\partial \delta_{1}}=-2 V\left(\pi_{1}\right)-\frac{\partial S W}{\partial \delta_{1}}=-V\left(\pi_{1}\right)(2+$ $\left.\frac{1}{x_{1}} \frac{\partial \pi}{\partial c_{1}}\right)$. 


\section{Appendix 5 (Proof for Proposition 5)}

We write (11) as $(\boldsymbol{B}+\boldsymbol{G}) \boldsymbol{x}=\boldsymbol{a}-\boldsymbol{c}$, and differentiate it with respect to $\delta_{1}$. The derivative of matrix $\boldsymbol{B}+\boldsymbol{G}$ is all zero except for the first diagonal element being $-\frac{2 \rho_{1}^{2}}{\left(\beta_{11}+2 \delta_{1} \rho_{1}^{2}\right)^{2}}$. So we get $-\frac{2 \rho_{1}^{2} x_{1}}{\left(\beta_{11}+2 \delta_{1} \rho_{1}^{2}\right)^{2}} \boldsymbol{\iota}+(\boldsymbol{B}+\boldsymbol{G}) \frac{\partial x}{\partial \delta_{1}}=\mathbf{0}$.

Hence we find $\frac{\partial x}{\partial \delta_{1}}=\frac{2 \rho_{1}^{2} x_{1}}{\left(\beta_{11}+2 \delta_{1} \rho_{1}^{2}\right)^{2}}(\boldsymbol{B}+\boldsymbol{H})^{-1} \boldsymbol{\iota}$.

(11) implies $(\boldsymbol{B}+\boldsymbol{H})^{-1} \boldsymbol{\iota}=(\boldsymbol{B}+\boldsymbol{H})_{1}^{-1}=-\frac{\partial x}{\partial c_{1}}$ and (10) implies $\beta_{11}+2 \delta_{1} \rho_{1}^{2}=$ $\frac{x_{1}}{p_{1}-c_{1}}$.

So we find $\frac{\partial x}{\partial \delta_{1}}=-2 \rho_{1}^{2} \frac{\left(p_{1}-c_{1}\right)^{2}}{x_{1}} \frac{\partial x}{\partial c_{1}}=-2 \frac{V\left(\pi_{1}\right)}{x_{1}} \frac{\partial x}{\partial c_{1}}$.

Also, as $\boldsymbol{p}=\boldsymbol{a}-\boldsymbol{B} \boldsymbol{x}$, we have $\frac{\partial p}{\partial \delta_{1}}=-\boldsymbol{B} \frac{\partial x}{\partial \delta_{1}}=2 \frac{V\left(\pi_{1}\right)}{x_{1}} \boldsymbol{B} \frac{\partial x}{\partial c_{1}}=-2 \frac{V\left(\pi_{1}\right)}{x_{1}} \frac{\partial p}{\partial c_{1}}$.

\section{References}

Amir, R., Erickson, P., Jin, J.: On the microeconomic foundations of linear demand for differentiated products. http://www.st-andrews.ac.uk/ wwwecon/repecfiles/4/1507.pdf (2015)

Amir, R., Jin, J.: Cournot and Bertrand equilibria compared. Int J Ind Organ 19, 144-145 (2001)

Amir, R., Jin, J., Pech, G., Troege, M.: Prices and deadweight loss in multiproduct monopoly. J Public Econ Theory 18, 346-362 (2016)

Asplund, M.: Risk-averse firms in oligopoly. Int J Ind Organ 20, 995-1012 (2002)

Baron, D.: Demand uncertainty in imperfect competition. Int Econ Rev 12, 196-208 (1971)

Batra, R., Ullah, A.: Competitive firm and the theory of input demand under price uncertainty. J Polit Econ 82, 537-548 (1974)

Cheng, H.: Bertrand vs. Cournot equilibrium with risk averse firms and cost uncertainty. Econ Theory 20, 555-577 (2002)

Eichengreen, B., Tobin, J., Wyplosz, C.: Two cases for sand in the wheels of international finance. Econ J 105(428), 162-172 (1995)

Eichner, T., Wagener, A.: Multiple risks and mean-variance preferences. Oper Res 57, 1142-1154 (2009)

Eichner, T., Wagener, A.: Tempering effects of (dependent) background risks: a mean-variance analysis of portfolio selection. J Math Econ 48, 422-430 (2014)

Hau, A.: Theory of the firm facing uncertain demand revisited. Econ Theory 24, 457-464 (2004)

Herranz, N., Krasa, S., Villamil, A.: Entrepreneurs, risk aversion and firm dynamics. J Polit Econ 123(5), 1133-1176 (2015)

Janssen, M., Rasmusen, E.: Bertrand competition under uncertainty. J Ind Econ 50, 11-21 (2002)

Jin, J.: Monopolistic competition and bounded rationality. J Econ Behav Organ 45, 175-184 (2001)

Leland, H.E.: Theory of the firm facing uncertain demand. Am Econ Rev 62, 278-291 (1972)

Levy, H., Markowitz, H.: Approximating expected utility by a function of mean and variance. Am Econ Rev 69, 308-317 (1979)

Markowitz, H.: Portfolio selection. J Finance 7, 77-91 (1952)

Markowitz, H.: Mean-variance approximations to expected utility. Eur J Oper Res 234, 346-355 (2014)

Sandmo, A.: On the theory of the competitive firm under price uncertainty. Am Econ Rev 61, 65-73 (1971)

Spulber, D.: Bertrand competition when rivals' costs are unknown. J Ind Econ 43, 1-11 (1995)

Tobin, J.: Liquidity preference as behaviour toward risk. Rev Econ Stud 25, 65-86 (1958)

Tobin, J.: A proposal for international monetary reform. East Econ J (East Econ Assoc) 4, 153-159 (1978)

Wambach, A.: Bertrand competition under cost uncertainty. Int J Ind Organ 17, 941-951 (1999) 